\title{
A Note on the Cover Art for Volume 6 (2021)
}

At Ledger, we welcome the submission of relevant and topical art for use on the cover of our issues. The cover art for this volume, Java (2020), by Celio RÜBEF, is a part of a project that explores the dichotomy between artistic and economic value through art. As the artist describes it:

"In this project, I solicit concepts of philosophy and economic theory to expand the boundaries of art definitions. By blending together conceptual art and visual art, I explore the ambivalent relationship between 'aesthetic value' and 'economic value' in art, and the effects on the contemporary artist's creative process who faces a dilemma between producing for creativity or the market. I use this theoretical framework to provide an artistic representation of this dichotomy using blockchain certification. By exploiting the 'error correction property', I alter QR codes while preserving their readability to generate certificates of authenticity that become themselves the artwork and call the observer to the resolution of the artist's dilemma."

The artwork also includes a QR code which, at the time of publication, links to an NFT minting and certification website - a relevant inclusion in a piece of art relating to cryptocurrencies. Ledger does not endorse nor does it take responsibility for the present or future contents of the aforementioned link. The QR code and link are published by Ledger only as components of the art on the cover. By following it, you agree to indemnify Ledger and its associated individuals and publisher from any liability based on doing so, including any direct or indirect damages or lost profits that may result. 